\title{
To Rebuild or to Refurbish? An Analysis of the Financial Convenience of Interventions on Urban Consolidated Contexts
}

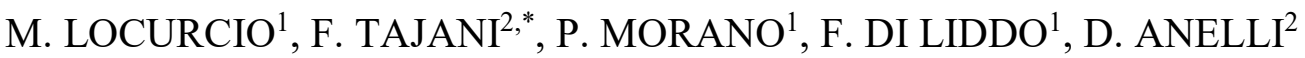 \\ ${ }^{1}$ Department of Civil, Environmental, Land, Building Engineering and Chemistry, \\ Polytechnic University of Bari, Via Edoardo Orabona, 4, 70126, Bari, ITALY \\ ${ }^{2}$ Department of Architecture and Design, Sapienza University of Rome \\ Via Flaminia, 359, 00196, Rome, ITALY
}

\begin{abstract}
In the current historical moment of post-crisis recovery, the real estate sector has a dual role: $i$ ) through the construction industry and its impacts on related economic sectors, it is called upon to be an active part of the economic recovery; ii) the enhancement of existing property assets is of primary importance in the containment of greenhouse gases and the achievement of the objectives set by the United Nations [1]. In this context, the various players involved in the real estate market have outlined the importance of being supported by assessment methodologies. That allows to point out not only the opportunities of the investment, but also the risks that may invalidate the initial forecasts, nullifying the success of the initiative. To this end, this research develops a multi-criteria Key Performance Indicator aimed at analyzing the feasibility of real estate initiatives that allows to provide a synthetic scoring on the financial sustainability of each investment and to compare different types of initiatives (e.g. new construction, demolition and reconstruction, renovation, etc.).
\end{abstract}

Key-Words: - financial feasibility, sustainable index, return on investment, renovation, real estate market, performance indicator

Received: June 12, 2021. Revised: November 17, 2021. Accepted: December 19, 2021. Published: January 15, 2022.

\section{Introduction}

Through the Green Deal [2] the European Union aims at achieving climate neutrality by 2050 and the intermediate target of a $55 \%$ reduction in $\mathrm{CO}_{2}$ by 2030 , in order to contain global warming by $1.5^{\circ} \mathrm{C}$. For these reasons, it is essential to direct investments towards sustainable projects and activities, making financial flows compatible with a path that leads to a development with low greenhouse gas emissions.

The real estate sector, in general, and the construction sector, in particular, have a decisive role in achieving these objectives; in fact, in Europe buildings and the construction sector are responsible for $35 \%$ of energy consumption and $38 \%$ of annual $\mathrm{CO}_{2}$ emissions [3]. Therefore, 8 of 17 Sustainable Development Goals (SDGs) defined within the 2030 Agenda [4] are related to the real estate sector which, in addition to being a powerful driver of the global economy, is also a crucial sector for the achievement of many of the SDGs. In this perspective, many studies [5-7] have highlighted the need to limit new construction ad to promote the recovery of the existing building stock, that is highly energy intensive, also by virtue of the absence of a housing demand related to the almost constant number of European inhabitants [8], the high demand for more comfortable residences form the thermo-hygrometric point of view and the need to contain the soil sealing [9].

The paper is structured as follows. In the second Section, the aim of the research is illustrated. In the third Section, the proposed model is explained. In the Conclusions, possible future applications are highlighted.

\section{Aim}

In the outlined scenario, real estate developers need to understand whether initiatives to rehabilitate existing property assets, in addition to being more sustainable from an environmental point of view, are more or less financially feasible than new construction/demolition and reconstruction operations. To answer this question, this research proposes a multi-criteria Key Performance Indicator (KPI) called Financial Feasibility Index $\left(I_{f}\right)$, which aggregates various parameters used in the analysis of the financial feasibility of real estate development interventions, by considering not only the yield of the initiative but also its riskiness with respect to the market in which it is located. This indicator allows: 
i) real estate developers, to compare different initiatives and identify the one that better performs; ii) professional investors (pension funds, retirement funds, etc.), to customize asset management with respect to different asset classes; iii) public entities involved in initiatives, to assess their chances of success. The Financial Feasibility Index thus provides a scoring of each real estate initiative analyzed, making it possible to compare different types of property investment in order to identify the best one in terms of profitability expectations and risk appetite of the individual investor.

\section{Method}

The selected parameters for the definition of belong to two different typologies, analyzed with respect to the specific characteristics of the Italian property market: the first typology concerns the financial feasibility of the single property initiative, whereas the second one characterizes the real estate market in which the initiative is located.

The financial feasibility of the single property initiative is carried out considering the expected future cash flows of the real estate investment and elaborating them through a Discounted Cash Flow Analysis (DCFA) [10]; the corresponding parameters are:

Internal Rate of Return (IRR), that is the actualization rate for which the Net Present Value of the initiative is equal to zero, i.e. the sum of the actualized revenues is equal to the sum of the corresponding costs;

Return On Sale (ROS), that is the ratio between the operating profit, calculate as earnings before interest and tax, and the market value of the property at the end of the initiative;

Return On Investment (ROI), that is the increase in the current value of investment compared to the cost of investment given by the historical cost;

Revenues/Costs Ratio $(R C)$, that is the ratio between the sum of the actualized revenues and the sum of the actualized costs.

It should be noted that, among the various parameters used to describe financial feasibility of an initiative, only the dimensionless ones have been deliberately considered, making subsequent normalization operations easier and reducing possible subjective aspects in the construction of .

In order to characterize the real estate market in which the initiative is located, three parameters have been constructed, by starting from the range of quotations provided every six months by the Italian
Real Estate Observatory (OMI) of the Revenue Agency for the period 2005-2020. Specifically, in order to dimensionalize the parameters, it has been necessary to build the hystorical series of average fixed-base quotations (quotation I semester 2005 $=100$ ) for the specific area in analysis; the first two considered parameters are:

- market risk, given by the standard deviation $(\sigma)$ of the average quotations on a fixed basis;

market trend, determined through the angular coefficient $(m)$ of the linear regression line constructed from the fixed-base average quotations.

A low-risk market is characterized by a zero standard deviation of quotations $(\sigma=0)$; a market will have a growing trend if the quotations tend to increase over time and therefore the angular coefficient of the regression of quotations is positive $(m>0)$, and vice versa.

The last parameter used of the construction of the is constituted by the market deviation $(\triangle M V)$, i.e. the percentage variation between the market value $(M V)$ per unit saleable surface at the end of the construction/refurbishment and the maximum quotation provided for the area where the intervention is located according with OMI in the second half of $2020\left(Q_{M A X}\right)$ :

$$
\Delta M V=\frac{\dot{M} V-Q_{M A X}}{Q_{M A X}}
$$

The greater $\triangle M V$ the more the initiative is misaligned with respect to the property market in which it is located, and this represents a potential obstacle to the marketing of the property when the intervention is completed; it should be noted that in the definition of $\triangle M V$ the maximum quotation has been considered, as it is reasonable to expect that, at the end of the intervention, the overall quality of the property will be higher than the corresponding average one in the reference area, and therefore the comparison should be carried out with respect to the maximum values of the area. $\triangle M V$ could also be much higher than zero in the event that the real estate development aims at intercepting a potential unexpressed demand and therefore not adequately detected through the OMI surveys.

Once all parameters that flow into the formation of $I_{f}$ are defined, they are aggregated using the weighted sum model, after determining the normalized value $\left(V_{i}\right)$ of each parameter and assigning the importance, i.e. the corresponding weight $\left(w_{i}\right)$ :

$$
\begin{aligned}
& I_{f}=w_{I R R} \cdot V_{I R R}+w_{R O S} \cdot V_{R O S}+w_{R O I} \cdot V_{R O I}+ \\
& +w_{R C} \cdot V_{R C}+w_{\sigma} \cdot V_{\sigma}+w_{m} \cdot V_{m}+w_{\triangle M V} \cdot V_{\triangle M V}
\end{aligned}
$$


The normalization consists in translating into the same scale (in the case in analysis " $0-1$ ") the values associated with the parameters characterized by either different units of measurements or very different ranges of possible values; in the present work the second situation has been considered, as all the indicators are dimensionless. In order to correctly normalize the values assumed by the different parameters, it is appropriate to define: $i$ ) the range of possible values; $i i)$ the function to be used for the normalisation operation. The range of the possible values assumed by the parameters has been defined with reference to the Italian context, whereas both the definition of the individual normalization functions and the assignment of weights have been delegated to a later phase; in this phase the list of the main normalization functions has been performed, delegating to a later date the calibration of the functions to be associated with each parameter and the assignment of the weights with respect to the specific risk/return profile (core, value added or opportunistic) of the investor, i.e. the decision-maker.

In Table 1, for each parameter, the goal of the investor and the range defined with reference to the Italian market have been reported; named $R_{M I N}$ and $R_{M A X}$ the values assumed by the parameters $P_{i}$, if the rare situations of exceeding the limits of the range $P_{i} \notin\left[R_{M I N} ; R_{M A X}\right]$ are verified, the minimum/maximum normalized value $\left(V_{i}\right)$ will be assigned, depending on the specific case study:

$$
\begin{aligned}
& \text { if } P_{i}<R_{M I N} \text { and goal }=\text { MAX } \Rightarrow V_{i}=0 \\
& \text { if } P_{i}<R_{M I N} \text { and goal }=M I N \Rightarrow V_{i}=1 \\
& \text { if } P_{i}>R_{M A X} \text { and goal }=M A X \Rightarrow V_{i}=1 \\
& \text { if } P_{i}>R_{M A X} \text { and goal }=M I N \Rightarrow V_{i}=0
\end{aligned}
$$

In order to identify and $R_{M I N}$ and $R_{M A X}$ of the parameters IRR, ROS, ROI, RC and $\triangle M A X$, several real estate development initiatives carried out by Italian property companies have been analyzed.

In order to define $R_{M I N}$ and $R_{M A X}$ of the parameters $\sigma$ and $m$, the corresponding database has been built for all the intended uses and all the areas of the series of fixed-based quotations for the period 2005-2020. In this case the data have been reported in a chart (Fig. 1), outlining almost normal distributions as confirmed by statistical tests, and the extremes of the range at the percentile of order 20 and 80 have not been considered. This assumption allows to avoid that specific conditions $\left(P_{i}<R_{M I N}\right.$ or $\left.P_{i}>R_{M A X}\right)$ determines an excessive contribute in the normalization.

Table 1. Main characteristics of the parameters

\begin{tabular}{llllll}
\hline No. & Parameter & Acronym & Goal & $\boldsymbol{R}_{\text {MIN }}$ & $\boldsymbol{R}_{\text {MAX }}$ \\
\hline 1 & Internal Rate of Return & IRR & MAX & $5 \%$ & $30 \%$ \\
2 & Return On Sale & ROS & MAX & $5 \%$ & $30 \%$ \\
3 & Return On Investment & ROI & MAX & $10 \%$ & $35 \%$ \\
4 & Revenues/Costs Ratio & $R C$ & MAX & 1 & 5 \\
5 & Market risk & $\sigma$ & MIN & 4.19 & 16.45 \\
6 & Market trend & $m$ & MAX & -0.85 & 0.52 \\
7 & Market deviation & MMV & MIN & $0 \%$ & $40 \%$ \\
\hline
\end{tabular}



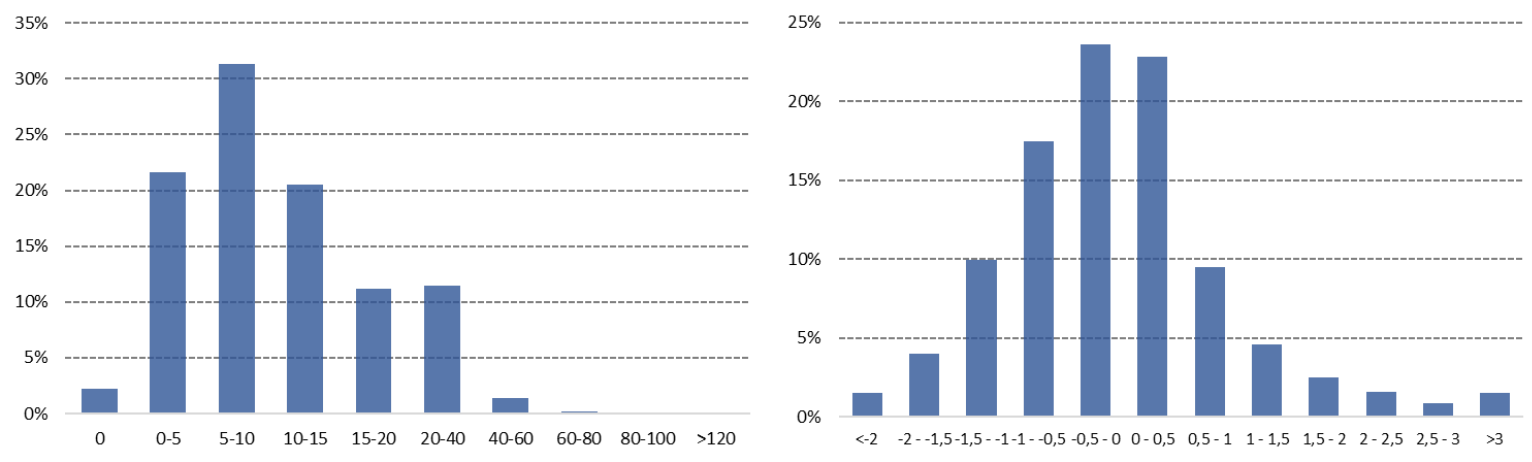

Fig. 1: Frequency distribution of $\sigma$ (on the left) and $m$ (on the right)

Once the range of possible values has been defined, the function to be used for the normalization operation, i.e. the function $V_{i}=f\left(P_{i}\right)$, can be chosen; in Fig. 2 the main normalization functions reported in the reference literature [11] and the relative equations have been summarized.

The last step necessary for the definition of $I_{f}$ is constituted by the assignment of the weight $\left(w_{i}\right)$ to the single parameters, according to the importance they have for the subject involved in the analysis of the different real estate interventions; it could be observed that investors with a low risk appetite will aim at assigning high weights to $w_{R C}, w_{\sigma}, w_{m}$ and $w_{\triangle M V}$, whereas investors interested in opportunistic initiatives will give higher weights to $w_{I R R}, w_{R O S}$ and $w_{R O I}$. Considering the limited number of parameters, one of the most effective procedures for assigning weights is represented by the Analytic Hierarchy Process (AHP), which provides the assumption that the decision-maker, during its choice, applies, more or less consciously, a hierarchy of all the several elements that are involved in the decisional process [12]. For the identification of $w_{i}$ the decision-maker is called to perform a series of pairwise comparisons among the criteria through some verbal judgments subsequently translated into numerical scores according to the semantic scale of Saaty [13].

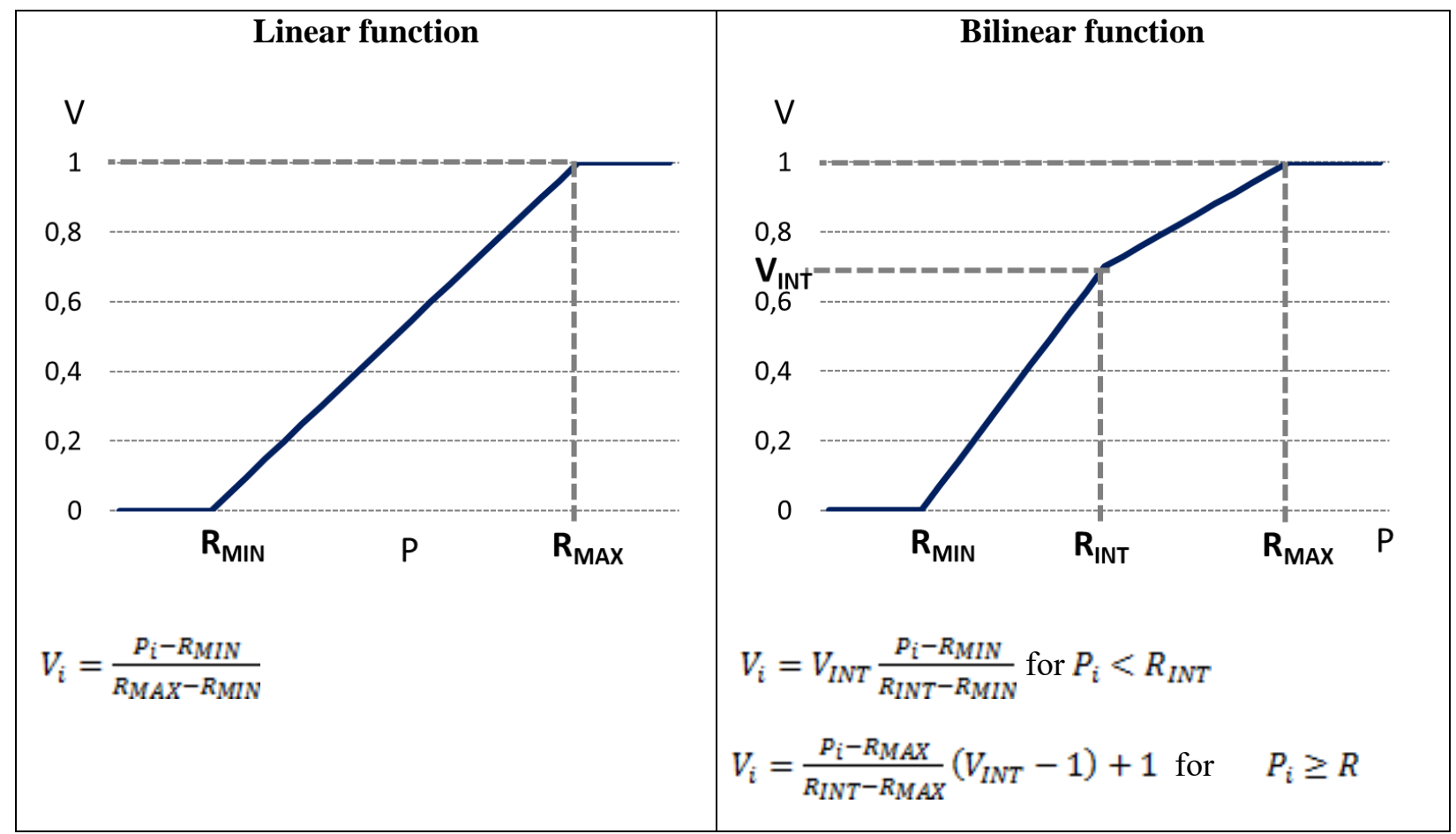




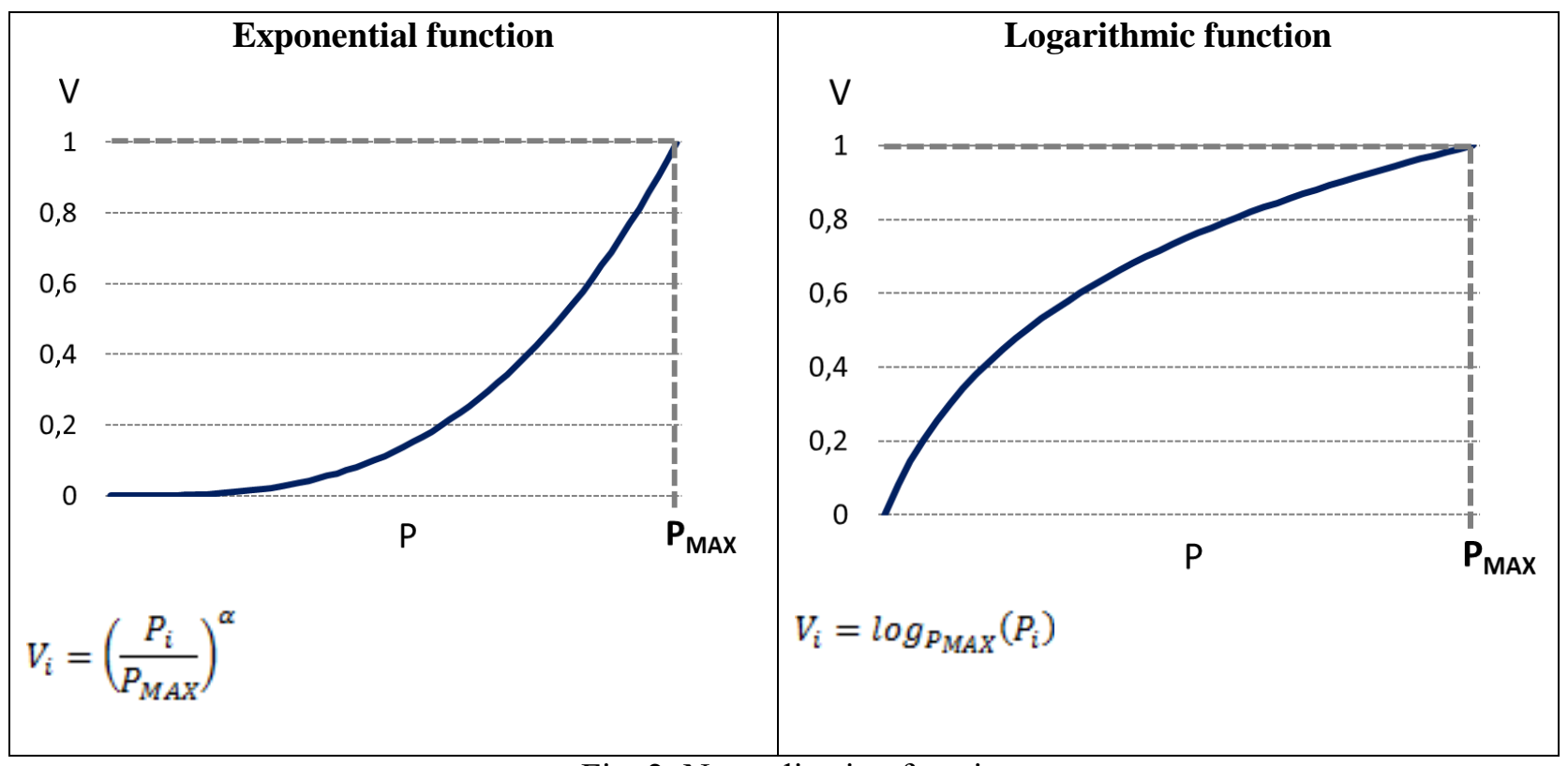

Fig. 2: Normalization functions

\section{Conclusions}

The current climate changes and the objectives of limiting the rise in temperature and consequently of $\mathrm{CO}_{2}$ emissions require a global review of the established development model; in this context of high uncertainty, international investors are directing their capitals towards Environmental, Social e Governance (ESG) compliant investments, that have reached in 2020 an Asset Under Management (AUM) equal to 270 billion dollars globally [14], surpassing in terms of market capitalization the Oil \& Gas sector [15]. In general, the real estate and the construction sectors have a decisive role in the current change through ESG compliant investment products that, by implementing sustainable strategies for the enhancement of existing real estate assets, seek to overcome the ordinary cultural resistance of a sector that is not prone to be modified. To this end, in the present research a Financial Feasibility Index $\left(I_{f}\right)$ has been defined, in order to allow the comparison among different types of property investments in terms of risk/return. This approach aims at highlighting that, in poorly predictable evolutionary contexts, the most resilient real estate investments, i.e. those able to elastically react to the shocks of a possible crisis, are characterized by energy-efficient properties, with high living comfort and located in built-up infrastructured areas. New constructions, realized in peripheral areas without urbanizations, characterized by a residential vocation and the absence of commercial activities, represent risky investments due to their location, that could cause rather long marketing times and consequently a high unsold.

Possible future developments of this work, also aimed at sorting out specific limits of the proposed method, could be: $i$ ) the development of a for different real estate initiatives, in order to outline their strengths and possible weaknesses; ii) the creation of a web tool for the application of the Financial Feasibility Index; iii) the appropriate definition of the ranges for all the considered parameters; $i v$ ) the choice of the percentile for the range definition of the market risk and the market trend; $v$ ) the real estate market characterization, that in this research has been carried out by considering only the data published by the Italian Revenue Agency.

\section{References:}

[1] United Nations. The Sustainable Development Goals Report 2020 Available online: https://unstats.un.org/sdgs

[2] European Green Deal 2021 Available online: https://ec.europa.eu/info/strategy/priorities2019-2024/european-green-deal/deliveringeuropean-green-deal_en\#documents

[3] 2020 Global status report for builindigs and construction. Towards a zero-emissions, efficient and resilient buildings and construction sector. UN environment programe. Global Alliance for Building and Construction

[4] United Nations. Agenda 20302015 Available 
online: https://unric.org/it/agenda-2030/

[5] Morano P, Tajani F, Di Liddo F, Amoruso P 2021 The public role for the effectiveness of the territorial enhancement initiatives: A case study on the redevelopment of a building in disuse in an Italian small town Buildings, 11(3), 87.

[6] Morano P, Tajani F, Di Liddo F, Anelli D 2020 A feasibility analysis of the refurbishment investments in the Italian residential market Sustainability, 12(6), 2503.

[7] Morano P, Locurcio M, Tajani F, Guarini M.R. 2014 Urban redevelopment: a multicriteria valuation model optimized through the fuzzy logic, in Murgante B. et al., Computational Science and its Applications, LNCS 8581, part. III, pp. 161-175, ISBN: 978-3-319-09149-5.

[8] United Nations Department of Economic and Social Affairs (UN DESA). Historical and projected population by world region https://www.eea.europa.eu/data-andmaps/indicators/total-population-outlookfrom-unstat-3/assessment-1 (avaible on line 14 July 2021)

[9] Morano P, Tajani F, Locurcio M 2015 Land use, economic welfare and property values: an analysis of the interdependencies of the real estate market with zonal and macro-economic variables in the municipalities of Apulia Region (Italy) International Journal of Agricultural and Environmental Information Systems, Vol.6, No. 4, pp. 16-39, ISSN: 19473192.

[10] Tajani F, Morano P, Di Liddo F, Locurcio M 2018 An innovative interpretation of the DCFA evaluation criteria in the public-private partnership for the enhancement of the public property assets, In: New Metropolitan Perspectives. Proceedings. SMART INNOVATION, SYSTEMS AND TECHNOLOGIES, Springer, ISSN: 21903018, Reggio Calabria.

[11] Ishizaka A and Nemery P 2013 Multi-criteria Decision Analysis: Methods and Software. John Wiley \& Sons., New Delhi.

[12] Saaty T L 1988 Multicriteria decision making - the analytic hierarchy process. Planning, priority setting, resource allocation, Pittsburgh: RWS Publishing.

[13] Saaty T L 2008 Relative measurement and its generalization in decision making: why pairwise comparisons are central in mathematics for the measurement of intangible factors - the analytic hierarchy/network process RACSAM-Revista de la Real Academia de Ciencias Exactas, Fisicas y Naturales. Serie A. Matematicas, Vol.102 No.2, pp. 251-318.MCSI 2020 ESG Investing. Better investments for a better world

[14] MCSI 2020 ESG Investing. Better investments for a better world

[15] FTSE Russel 2020 Investing in the green economy - sizing the opportunity

\section{Creative Commons Attribution License 4.0 (Attribution 4.0 International, CC BY 4.0)}

This article is published under the terms of the Creative Commons Attribution License 4.0 https://creativecommons.org/licenses/by/4.0/deed.en $\underline{\text { US }}$ 